\title{
Challenges of Protected Area Management and Conservation Strategies in Ethiopia: A Review Paper
}

\author{
Wondimagegn Mengist* \\ Department of Natural Resource Management, Debre Berhan University, Debre Berhan, Ethiopia
}

\begin{abstract}
The history of Protected Areas (PAs) in the country goes back to Zere Yaecob in the $15^{\text {th }}$ century. The modern way of biodiversity conservation was started during the reign of Menelik II and the official establishment of National Parks was started in the 1960 's. Since then PAs are facing different challenges. The scientific literature contains numerous descriptions of the challenges of protected area management that causes a devastating impact on wildlife. This review paper, therefore, covers six major challenges of PAs management in Ethiopia and their shortcomings. Though the size of PAs is increasing in the country most PAs are under human-induced pressure. Most of them have challenges and strong pressure from the local community. The local people living in and around parks and other PAs are poor and their livelihood is directly linked with natural resources. Some of the major challenges are encroaching PAs for farmland expansion, settlements, livestock grazing, and illegal hunting. These are coupled with weak policy enforcement, climate change, and the introduction of invasive species. As a result, the status of PAs in Ethiopia is poor and the wildlife is declining from time to time, and many of them are also on the verge of extinction. Therefore, the national and regional governments, local people, and any other governmental and non-governmental bodies, and scholars in the area should plan effective management strategies that can help to reduce the pressing problems on wildlife in particular and the entire PAs ecosystems in general.
\end{abstract}

Keywords

Challenges of protected areas, Ethiopia, Protected areas, Wildlife, Conservation strategies

\section{Introduction}

The establishment of protected areas (PAs) is a cornerstone of global conservation strategies [1]. According to the International Union for Conservation of Nature (IUCN) definition, protected area has been defined as '[a] clearly defined geographical space, recognized, dedicated and managed, through legal or other effective means, to achieve the longterm conservation of nature with associated ecosystem services and cultural values' [2]. In addition to biodiversity conservation, PAs can provide different ecosystem services [3]. They are useful for reducing resource exploitation levels from PAs like deforestation in terrestrial biomes and supporting the management of threats within PAs such as control of invasive species of plants and animals [4].

The practice of conservation has a long history in Ethiopia which dates back to Emperor Zerea Yacob (1434-1468) [5]. The emperor recognized the existence of deforestation in Wechecha Mountain near Addis Ababa and he ordered to replant the area using different seeds collected from Wof-Washa forest in central Ethiopia. This took place over 550-years-ago and today the area is known by the name "Menagesha State Forest". Undeniably, this area could be claimed as the oldest conservation practice in Africa [6]. Later during the reign of Emperor Menelik II in 1909, a formal way of pro- tecting wildlife began and the policy prohibited the illegal killing of wild animals [7].

Since then, therefore, PAs were seen as a key to conserve wildlife. Currently, Ethiopia becomes one of the few countries in the world which is expanding PAs to conserve fauna and flora with a high level of endemic species in the country [8]. Besides, the country ratified the Convention on Biological Diversity $(C B D)$ by realizing that the existed biodiversity needs conservation and protection mainly from anthropogenic factors [9]. The current government, as opposed to the previous, uses a community-based approach to share benefits and ownership rights to local people. Thus, PAs were controlled and managed by regional governments and the Ethiopian Wildlife Conservation Authority (EWCA). EWCA has the au-

*Corresponding author: Wondimagegn Mengist, Department of Natural Resource Management, Debre Berhan University, Debre Berhan, Ethiopia

Accepted: May 16, 2020

Published online: May 18, 2020

Citation: Mengist W (2020) Challenges of Protected Area Management and Conservation Strategies in Ethiopia: A Review Paper. Adv Environ Stud 4(1):277-285 
thority to manage those PAs which lack sufficient management system and located within two or more regional states as well as those with more endemic species [10]. However, the management of the National Park which was under the respective regional state was given back to the federal government under the EWCA due to the absence of sound effects on the conservation and sustainable utilization of Pas [11]. Though the country is rich in plants and animal species, of which some are endemic species, the conservation policy since the previous time was not effective to protect the wildlife with their natural habitats from deterioration and extinction. These increased the number of threatened and endangered plant and wild animal species list, and a high level of habitat modifications [12].

At different sites of the country, several National Parks, sanctuaries, wildlife reserves, and controlled hunting areas were established [13]. The share of PAs from the total land size of Ethiopia is large though the data showed variation across sources. For instance, according to IBC (2009) report, it covers $19.05 \%$ whereas it is believed to be above $17 \%$ [14], and $14 \%$ based on EWCA (2012) report. The other source also mentioned that the PAs in the country has reached about $15 \%\left(213,464 \mathrm{~km}^{2}\right)$ area to conserve wildlife. It is assigned for National Parks, wildlife sanctuaries and reserves, controlled hunting areas, and community conservation areas [5]. This variation might be emanated from the time of collecting the data and again due to the re-demarcation of protected area boundaries.

The total numbers of PAs are increasing; however, up to now only a few of them are gazetted. At most both the gazetted and the non-gazetted PAs are facing pressure from the human population. Compared with many countries in Africa, Ethiopia is economically the poorest and a highly populated country. Based on the central statistical agency projection, more than $80 \%$ of the population is living in rural areas on subsistence livelihoods and dependence on natural resource extraction like arable lands and forests [15]. The existence of large population size in and around PAs creates serious challenges over natural resources in general and wild animals in particular because their life is directly linked with natural resources. If the appropriate solution is not employed on the people living adjacent to PAs, they will keep on creating impacts. According to many studies, some of the most common human effects over PAs are livestock grazing, deforestation, illegal hunting, encroachment by agricultural and settlement expansion, pastoralist movement in the park looking for pasture for their livestock, disease transmission (mainly from domestic animals to wild animals), lack of community participation and climate changes, and habitat fragmentation and loss [5,16-19]. The problem is worsened due to the absence of a strong network between PAs and management plans [20].

PAs were often created for biodiversity conservation and they can also provide other benefits like recreation, tourism, and education [21]. Therefore, to combat the anthropogenic causes and challenges over PAs, promoting responsible tourism is needed. This is linked to sustainability initiatives such as "alternative tourism, ecotourism, ethical tourism, green tourism, soft tourism, pro-poor tourism, geo-tourism, inte- grated tourism, community-based tourism, etc. it also demarcates an analytical realm of its own" [22]. Such types of (eco) tourism can be enabling local communities to improve their wellbeing via increased socio-economic benefits, develop belongingness, and similarly improve natural resource management [23]. PAs ecosystems can deliver benefits from both ecological and economic points of view to societal well-being. Therefore, there should be an adequate monetary investigation on the number of benefits they earn and in turn the cost they bring on the natural resources found in PAs [24].

The review work, therefore, formulated specific research questions. These were: (1) What are the major threatening factors for wildlife resource degradation and deterioration in Ethiopia? (2) What is the current wildlife conservation approaches? And (3) what are the lesson learned and the way forward for the sustainability of wildlife and their ecosystems? The motive of this overview work was to highlight the current state of PAs in the country, major challenges that put pressing problems over the wildlife of PAs and its entire ecology; providing useful information for conservation policies and academia, and to equip protected area practitioners with the recent and appropriate information to identify the proper solution for the gaps to be filled by future research works. Therefore, the work helps to define the status quo and deepen the existed condition of PAs. To that aim, the review addressed the following specific objectives: (i) To discuss the major challenges of PAs in Ethiopia, (ii) To state the conservation strategies and their drawbacks on the wildlife resources of the country, and (iii) Finally, to forward possible solutions for the sustainability of the wildlife conservation in one hand and wise use of its resources for socio-economic developments.

\section{Literature Search}

This work is based on secondary sources of information using literature searches. The search for this review includes mainly internet searches for online reports, manuals, and scholarly articles provided by reputable organizations such as Science Direct, Scopus, and Google Scholar. Relevant pieces of literature were reviewed on concepts of PA, challenges of PA management in Ethiopia, trends of natural resource conservation policy, and approaches from the selected databases.

Search terms and keywords such as "protected areas", "challenges of protected areas", "natural resource conservation policy", "conservation approaches of protected areas", "National Parks", and "forest priority areas" were used, with the results further refined with the keyword of "in Ethiopia". The inclusion and exclusion criteria used during the review were: (i) English-language publications and (ii) Published in peer-reviewed scientific journals. However, the size of published literature in peer-reviewed was too small and thus, the search was extended to cover grey literature such as scientific reports, proceedings, and unpublished data. All the selected literature was examined to extract meaningful information to achieve the review objectives. Besides related literature were added by reviewing the reference lists of selected literature through backward reference list checking [25] which evaluat- 
ed protected areas that also conformed to the criteria listed above.

\section{Major Challenges and their Shortcomings for PAs in Ethiopia}

The country has established several PAs that includes 21 National Parks, three sanctuaries, three wildlife reserves, 20 controlled hunting areas, six open hunting areas, six community conservation areas and 58 national forest priority area of which 37 are protected forests [26]. There are also two Men and the Biosphere Reserves registered under the United Nations Educational, Scientific, and Cultural Organization [27]. However, the $21^{\text {st }}$ century PAs governance bodies have encountered enormous challenges because "the footprint of human disturbance and change can be seen on every continent of Earth including Antarctica" [28]. Therefore, the following six subtopics were concentrated on the major challenges that jeopardize the objectives of most PAs in Ethiopia. Most PAs in the country are facing either one or most of the following challenges.

\section{Human encroachments}

During the Derg regime, there was an expansion of commercial state farmlands and this move consumed more grazing areas and other communal lands. Then the local people had little pasture lands for their cattle mainly in Bale area and the pressure on PAs increased as the population number kept on growing [16]. In Bale Mountain National Park, there was serious livestock grazing and dog contact with wild animals. The livestock competed with wild herbivores like Nyala for grass and water. More cattle population means high feed competition with rodents- which was the main source of feed for Ethiopian wolf [16]. Vial, et al. [29] discusses the abundance of domestic livestock in Bale Mountain National Park and their consequences on Ethiopian wolves. The livestock damaged the vegetation cover, its diversity, and its composition. It also affected the rodent population by reducing the biomass available for them and the composition of rodents. In sum, it impacted the wolf main source of feed-rodents. The entrance of dogs in the park resulted in outbreaks of rabies which killed almost $77 \%$ of Ethiopian wolves in Bale Mountain National Park between November 1991 and February 1992 [16]. In the same park from 1992-2010, at least three outbreaks of rabies had occurred and each incidence might have killed about $50-76 \%$ of the wolves. Also, the dogs in the park resulted in competition with Ethiopian wolves for prey and hybridized with wolves $[16,29]$. Breeding of wolves with domestic dogs is a threat to wolves' species and also indicators for the intervention of human settlement inside PAs [8]. In contrast to Stephenes, et al. [16] and Vial, et al. [29], dogs in the Bale Mountains feed humans on waste products during food preparation, leftover human foods, and any dead animal carcasses. The share of wild animals mainly rodents for dog feed is insignificant and the study concluded that there is no strong competition between dogs and Ethiopian wolves on rodents [30].

According to the study of Yosef and Afework [19] in the Bale Mountains, the encroachment affected wild animals mainly mountain Nyala by creating a food shortage and affecting their movement in the park. The livestock accessed and grazed grasses in the park and the community also harvest wood, expanding their farming lands and settlement areas in the park. As a consequence, the number of mountain Nyala population decreased. According to Yosef [19], people living adjacent to parks in the future have a desire to keep more cattle size and freely accessing grazing areas in the national park. The rate of deforestation is also accelerated when the pastoral society gradually shifts to sedentary farming where both cultivation and rearing animals are their main livelihoods. Similarly, in Abijata-Shalla National Park, there is severe population pressure over natural resources. They expand their farming lands and grazing areas in the park. Most of the people have small landholding size and the population size is also increasing. They viewed that the existence of the park limited their economic development and they criticize as they are unable to expand their farming and grazing lands and utilizing other natural resources in the park as they can. Shortly, therefore, the pressure over the park will be higher as population number is growing and the regulation of park is not able to compromise the interest of the local people and the conservation of the park [18].

According to Demeke and Afework [17] in Nechisar National Park, the impact of human population pressure over the park was serious. The local people are pastoral society and they keep on large herds of livestock which leads to competition for pasture, water sources, and space with wild animals. The existence of a large livestock population could change both the structure and composition of plant species. On the other side, the local society viewed having a large cattle population as sources of income and as a measure of wealth status/rank in the community. However, these large cattle populations result in strong pressure over the park's natural resources [31]. The occurrence of local people settlements around the park also aggravated the extraction of a natural resource from the park. These circumstances negatively affected Swayne's heartbeast population in the park like exposing them for predators and hunters, increasing their chances of sharing diseases from domestic animals, and reducing the available natural area for grazing and mating [17].

Based on Stephenes, et al. [16] discussion, the expansion of both human settlement and livestock population in and around the National Park could have three main effects. First, the livestock population consumed plants and reduced the available plant species and its natural beauty which in turn affects the wild fauna diversity in the site. Second, the livestock population disturbs the tourism sector by reducing the tourists' mobility and impaired their visual observation of wild animals. Third, in areas where competition for resources is high, wild animals like Nyala have been reduced. The dogs follow the livestock seriously influencing the wild animals by feeding on the calves of Nyala.

In Awash National Park, intertribal conflict and livestock grazing are the two most pressing problems. The park is inhabited by Kereyu, Afar, and Ittu tribes. They compete for the pasture and water during the dry season and conflict between the tribes is common. The livestock enters the core ar- 
eas and the existence of a large herd of livestock also exploits the resources needed for the wild animals [32].

Human encroachment in PAs also worsens human-wildlife conflicts (HWC). HWC happens when wild animal's requirements overlap with those of human populations (IUCN, 2017), and when there is an increase in the human population, there will be competition with wild animals on space and utilization of resources. HWC results in nearby people by livestock predation, crop-raiding, and diseases [33]. Although the effect depends on the species type, large herbivore mammals are causing damage to crops and plantation [17]. As an example, in Chebera- Churchura National Park, carnivore attack between 2007-2011 caused loss of 30\% of the livestock of the area $[33,34]$. Similarly, in Babile Elephant Sanctuary, human-elephant conflict occurred from 2004 to 2008, elephants causing loss of crop whereas human revengeful killing six elephants [33]. According to Alemayehu, et al. [34] in Chebera-Churchura National Park, one of the causes of HWC is crop raiding. Primates raid crops and the rate of crop damage is more serious in villages closer to the park. The effect of HWC can extend up to human attacks particularly when they walk alone and in the evening time. Therefore, all these unwanted acts resulted from the existence of weak law enforcement in PAs in Ethiopia.

\section{Habitat fragmentation and losses}

Deforestation in and around protected areas is causing habitat loss and fragmentation which in turn impact the wild animals in many ways. The wild animals lose their habitat, sources of food, and spaces due to loss of biodiversity, land degradation, and encroachment [35]. Anthropogenic activities in PAs are responsible factors for habitat fragmentation in too many smaller patches, the widening distance between patches, and gradual loss of habitats. This makes the fragmented habitat to be less suitable for wild animals and species activities are restricted within the created small patches. This again results in the introduction of non-native species, parasites, and altering the micro-climate of the area [36]. For instance, some PAs are crossed by road lines like Awash National Park, Yangudi Rassa National Park, and Allideghi wildlife reserve area. No doubt, the road construction has economic importance for the country, but it does not address the needs of the wild animals in each park. As a result, many wild animals are killed by a car accident. Along the side of the road, there is deforestation, pollution, and contamination that cause impacts on the wild animals. Some wild animals are confined to the patches created by road lines [35]. Besides, the roads increase the edge effect and human beings access and disturb wildlife. The illegal poachers can easily exercise wild animal hunting and the road noise can also disturb the wild animals. The invasive species are invading areas adjacent to the roadsides [36], for instance, the invasive plant species of Prosopis juliflora is common in Awash National Park and areas outside the park.

Habitat fragmentation leads the area to be less comfortable for wild animals and the animals cannot get all their needs from the area. They are forced to wandering the nearby area for looking for resources. Mainly the buffer zone is mod- ified by humans and the herbivores are forced to use crops as sources of feed. This triggers the HWC because the disappearance of this buffer zone creates close contact between wild animals and the human population [33]. As a result, most dwellers near PAs have developed resentment towards wild animals and viewing them as not valuable assets [17].

According to Mohammed and Afework [36], habitat fragmentation has long-term effects on species demography and genetic make-up. The physical presence of barriers can have five primary effects. These are a loss of habitat area, disturbance/edge effects, mortality like the roadside killing of wild animals, isolation of animal population, and corridor. Furthermore, infrastructure construction accelerates the modification of the natural wildlife habitats, increasing human disturbance and hunting, the introduction of non-native species, and stiff resource competition.

\section{Illegal hunting and poaching of wild animals}

Illegal wildlife hunting and trading have received international attention and a recent report by the United Nations Environment Programme who notes the importance of designing various techniques to illegal hunting of different value species like "including demand reduction campaigns, use of anti-money laundering regulations, development of surveillance networks, and increased use of force" [37]. Illegal hunting is a threat to wildlife conservation works in Africa and it is a common practice in Ethiopia. It can be fueled by various factors that can range from simple social prestige which is connected to bravery and manhood, the need of wild animals' meat for consumption, and commercial trading of valuable parts of the animals $[37,38]$. They used hunting methods like snaring, poisoning, and firearms. Out of them snaring is one of the undesirable hunting techniques from its non-selective trapping of animals, difficult to locate and control where it is placed [38]. According to Nishizaki [39], after the downfall of the Derg regime in 1991, the local people greatly exercised wild animal killing in Mago National Park. The ethnic groupAri, Banna, Hamar, Kara, Muguji, and Mursi- rely on natural resources in the park for their fodder, firewood, and food. These six ethnic groups are settling at the edge of the park and having automatic rifles makes their hunting of wild animals easy. Until the government can stop the practices, the wild animal populations keep on decreasing dramatically [39].

According to Getachew and Weldemariam [35] report, trafficking of a wild animal is common in Ethiopia. Illegal traders are easily transporting trophy and skull of wild animals which have commercial importance in the global illicit market using the eastern road line. The customs line is weak to check the individual transport system and the poachers are using this advantage to cross the boundary line.

\section{The inconsistency in wildlife conservation office and policy}

The wildlife conservation sectors had experienced fluidity as the regime had changed. In 1944 the sector was under the Ministry of Agriculture and in 1965 the Ethiopian Wildlife Conservation Organization (EWCO) was established under the Ministry of Agriculture. The wildlife regulation policy in 1972 
also prohibited community participation and wildlife hunting within National Parks. The military government maintained the previously formed wildlife management policies and in 1980 established the Forest and Wildlife Authority. The approach during the Derg regime also limited people's participation and applied fence and fine for resource protection [7]. The new government, Ethiopian People's Revolutionary Democratic Front (EPRDF), shifted the responsibility of forest and wildlife to the Ministry of Natural Resources Development and Environmental Protection in 1993; to Ministry of Agriculture in 1995; then to Biodiversity Conservation and Research Institute in 1998; to the Ministry of Agriculture and Rural Development in 2003 [7]. Formally, EWCO had changed its name to EWCA in 2007 and became under the Ministry of Culture and Tourism aimed to manage and conserve the protected areas of the country $[7,40]$.

The policy issue focuses on exclusionary PA policy and other policies like resettlement and villagization program. During the imperial period, the country adopted the IUCN standard of "exclusionary protected-area policy". Following that the policy implement limits people from having access to species and other natural resources, which was not regulated before. Even during the military regime, the restriction was increased and EWCO empowerment and public endorsement increased. During these two regimes, the country was in a civil war and there was an involuntary settlement program. These two-event resulted in insufficient finance for the conservation program, decreasing income from PAs, and in turn aggravated rate of loss of natural resources of PAs. Also, the policy is excluding the local people from benefit-sharing and saying. As a result, during the transition period- which was a time of disorder and lawlessness common, the local people damaged PAs severely by exploiting forest and wild animals [12].

Based on the principle of decentralization on natural resource management, in 1995 most of the PAs in Ethiopia were shifted from the Federal Bureau of Wildlife Conservation Authority to respective regional level administration [7]. The intention was to allow regional bureaus to make structural arrangements to implement decentralization in terms of creating a conducive environment for sustainable resource management [41]. Also, the government of Ethiopia allowed African Parks, non-governmental organization, to manage Nechisar National Park in 2004 and Omo Park in 2005 but withdrawn in 2008. Recently the federal government started to regain control over PAs from regional governments [7]. Such inconsistency on the approach over the park management opened room for the degradation and exploitation of natural resources. The status of most PAs is declining from time to time due to the weak protection of wildlife. Therefore, the wildlife policy promotes a development-oriented way of conservation approaches. However, there is no clearcut line between decentralization vs. centralization, community-based conservation vs. fortress conservation, rather mixed approaches are observed.

\section{Wildfire}

In the rural area of Ethiopia, the fire has both ecological and economic benefits. They use it for clearing lands to expand farming areas, to facilitate new grass growth for their domestic animals, to eradicate different insect pests like tsetse fly or ticks and wild animals that raiding crops as well as to limit hiding places for large predators $[42,43]$.

Fire is common in lowland and midland areas of Ethiopia. In 2000, a fire occurred in highlands and high forest areas. It covered Bale, Borena, Jimma, Illubabor, part of Welega, Harerge, Arsi, Benishangul-Gumuz, Gambella, and SNNPRs. Many other national forest priority areas were also affected by fire burning [42]. The incidence of fire outbreak was common in different parts of the country and only a few studies were conducted on the effects of fire on plant biodiversity [42-44]. However, there is no in-depth scientific study that covered the impacts of fire on fauna biodiversity in Ethiopia. For instance, the fire caused great damage to Bale mountain massifs. Before 2000, fire outbreaks in the area affected the ericaceous vegetation. More fire occurred between February and April of 2000. From all historical fire incidences in the area, it was the worst and destroyed more than 90 thousand hectares of forest cover. After eight years, another fire occurred as the second-worst fire and covered nine districts of the Bale zone. These recurrent fires outbreak caused countless impacts both on the plants and wild animals [44].

In 2001, with unknown sources and causes, the Awash National Park was set under fire on two occasions during June and November that covered about 5 and 6 hectares of land respectively [42]. Although there are no scientific studies on the side effects of fire incidence in forests and wild animals in the National Parks of Ethiopia, wild animals were impacted directly by the fire burning and indirectly by losing their habitats and feed sources. A few months ago, in 2018, a forest fire occurred in southwest Ethiopia in Sheka biosphere reserve and greatly damaged the natural forest resource. The effect of fire is expected to be the worst on plants and wild animals. It damaged more than $\mathbf{2 0 0}$ hectares of the forested area together with different insects and other wild animals living inside.

\section{Climate change and the introduction of exotic species}

Both climate change and invasive species are the two main threats for both plant and animal species in PAs. The consequences of climate change on biodiversity are more severe where the area has high biotic diversity and the study also in the threshold of extinction [45]. The same is true in Ethiopia where the country has high species diversity. Moreover, the other consequences of climate change are range shifts that may cause the species to move out from the range of protected areas. These range dynamics due to climate change will reduce the suitability of reserving wildlife in fixed protected areas [46]. This may result in competition for resources and changes in the way predators interact with their prey. Moreover, the PAs character limited wildlife mobility to relocate to new geographic areas in response to climate change [47].

Climate change is also having significant effects on wildlife and their ecosystems. These were caused due to the occur- 
rence of invasion by new plant and animal species including plants, animals, and pathogens; reductions in population size mainly for boreal or montane species; an increase in dissemination of wildlife diseases and parasites, and increased spread of invasive species [48]. In a normal circumstance, diseases are transmitted directly from infected to healthy ones through infected prey or biting insects. However, indirectly the occurrence of climate change enhanced the rate of disease transmission and increased pathogens within intermediate hosts and vector [49].

The introduction of non-native species has its drawbacks on the wildlife resources of the country. For example, Prosopis juliflora species was introduced in Ethiopia around the 1970s in semi-desert and desert parts of the country for watershed protection. This area hosts many endemic plant and animal species. It harbors vulnerable and threatened wild mammals like African Wild Ass (endemic) and Grevy's Zebra. However, the introduced species is an invader and took advantage of the native species. It reduced the native browsing trees/shrubs and grasses which is a feed of both the wild and domestic animals in the region and denied access to available grasses [50].

\section{Conservation Strategies of PAs in Ethiopia}

\section{Centralized approach: Governance by govern- ment}

Under such an approach the central government who were responsible and accountable for managing the natural resources. The central government had exclusive authority to control PAs and takes decisions such as "determining its conservation objectives, and determining and enforcing its management plan". This kind of approach allowed the central government to establish PAs without adequate participation and consultation of the local community and other stakeholders [51]. Historically, to protect this diverse plant and animal species from extinction and misuse, the central government of Ethiopia designed a centralized approach to the conservation of PAs. The approach was "people out" that excluded the local people's participation in PA management. This approach ignored the needs of the local people and alienated them from the resources. It was difficult to enforce conservation policies and regulation, rather the rate of biodiversity loss was high [5].

Although Ethiopia is rich in both fauna and flora species of which many of them are endemic species, the conservation and protection measures were fewer effective. Because one of the major factors was the inconsistency of its wildlife conservation policy and instability of regimes that opened room for illegal exploitation and degradation of resources in PAs. Thus, most of the historical governments had limited success in conserving natural resources. Compared to the potential of the natural resource, its diversity, and abundance of natural resources of the country, the extent and amount of PAs conservation and expansions are negligible. Besides, the extent and amount of natural resource damage during the transition period of 1991 were serious in the country [5].

According to Asebe [52], the exclusionary conservation approaches of the National Parks in Ethiopia are less effective. The intensity of conflict of interest between the local people and the park was high. Because the approach made the local people loser. They lost their attachment and ownership rights of the resources. That is why the local people as revenge against the system affected the natural resources during the unstable period in 1991. Besides, this led to the loss of conservation-related income at the national level.

\section{Decentralized approach: Shared governance}

According to Worboys, et al. [51] description, shared governance refers "governance is based on institutional mechanism and processes by which authority and responsibility are shared among two or more actors". As opposed to the centralized approach of the year before the 1990s, recently the federal government of Ethiopia allowed the participation of local people and non-governmental organizations in PAs management. Power decentralization in Ethiopia is mainly supported by the 1995 FDRE constitution under Article 50(4) which states as "State government shall be established at the state and other administrative levels that they find necessary. Adequate power shall be granted to the lowest units of government to enable the people to participate directly in the administration of such units" [53].

Though it is limited and practiced in few PAs, there is a benefit-sharing mechanism to local people from the tourism sector under the ecotourism sense; mobilization of the financial and labor resources from local people to the conservation of wildlife and allowing the regional bureau to decide their utilization preferences [5]. The application of the participatory protected area principle is with the expectation of win-win outcomes both for the biodiversity and local people/economic development. If the local people get an advantage from the given PAs, they will give their support for conservation, guarding for the resources by controlling the illegal users and able to make a decision that supports the conservation works.

The decentralized approach gives room for traditional knowledge for resource conservation. Indigenous people have unique knowledge of their environments because they are bounded by their environments, its time and space limited and they viewed nature as sacred. As a result, they lived with nature with respect, trust, and live in harmony with nature [52]. However, this new approach has also a limitation because giving responsibility to some of the National Parks for the regional bureau is unable to reduce the pressure coming from livestock and other human pressure. Therefore, PA management needs strong enforcement and revisiting the policy implementation.

\section{Conclusion}

The country has a wide variety of PAs at different ecological sites and has great economic and environmental importance beyond its fundamental role in the conservation of wildlife. However, the wildlife in almost all National Parks and other reserve areas are under great pressure due to poor PAs conservation strategies and policies coupled with anthropogenic pressures. It is, therefore evident that there is an expansion of human settlements, farming lands, and livestock 
grazing inside reserve areas. There are also illegal hunting and poaching of wild animals, disease transmission from domestic animals to wild animals, and an introduction of exotic species which have a consequence on wildlife habitats. These all lead to the exploitation and degradation of biodiversity resources in PAs. PAs in Ethiopia, therefore are the so-called 'paper parks' due to the absence of strong management strategies and consistent wildlife policy for conservation schemes.

Consequently, limiting the rate of human encroachments, habitat fragmentation, illegal hunting, wildfire, and avoiding inconsistency of laws on PAs can help to manage and conserve the wildlife resources and their ecosystems effectively. Therefore, this necessitates the formulation of strong leadership and effective management strategies. These can be achieved by employing the best management expertise, experience, and equipment available in the $21^{\text {st }}$ century that can help to bring effective conservation of wildlife in Pas.

\section{The Way Forward}

The following points are forwarded as a solution for the health of the wild animals and their ecosystems in general. Therefore, properly addressing the following points can help to improve the status of PAs and the wellbeing of wildlife.

These are, first adapting the poverty reduction strategy/ policy. The local people are encroaching PAs to expand their farming lands and grazing areas. This can be reduced by using strategies like subsidizing agricultural inputs, facilitating credit access, expanding their market access, and improving their poor way of farming. These will allow them to produce more from a small plot of lands and indirectly reduce their pressure over PAs. Besides, there should be additional income sources for the locals using responsible tourism such as ecotourism activities like renting of pack animals, being local guidance, and selling of cultural materials. These can build belongingness of local people to the PAs and also means of sharing benefits to them.

Second, the main and the long-lasting solution is controlling the population growth rate in the site in particular and at the country level in general. The proper way will be reducing the number of new immigrants to PAs, expanding access to family planning services, and depopulating the area. One of the mechanisms is reducing the number of people joining the farming sector as a livelihood. Third avoiding development programs at the cost of PAs. Road construction and commercial farming are factors that reduce the size of PAs and increase the vulnerability of wild animals in Ethiopia. As a result, when the regional or federal government designs roads, they should look at areas with less impact on conservation sites. The commercial farming, mining, and coffee or tea plantation should not be located in PAs at the cost of wildlife resources.

At last, expanding education and awareness, and scientific research on wildlife should be given priority. Improving the awareness level of society may help to reduce the impacts on wildlife. Making scientific research is also valuable to look better solution for the enhancement of conservation areas in general and wildlife species in particular.

\section{Acknowledgment}

I would like to appreciate the two anonymous reviewers for their valuable and constructive comments on the previous version of this manuscript. I am also thankful to Debre Berhan University and Addis Ababa University for making it possible for me to pursue my education here. I am also grateful to Professor Afework Bekele for his editorial contribution to improve the quality of the paper.

\section{Funding}

This research did not receive any specific grant from funding agencies.

\section{References}

1. Dearden $P$, Bennett $M$, Johnston J (2005) Trends in global protected area governance, 1992-2002. Environmental Management 36: 89-100.

2. Dudley N (2008) Guidelines for applying protected area management categories. IUCN, Gland.

3. Schirpke U, Marino D, Marucci A, et al. (2017) Operationalising ecosystem services for effective management of protected areas: Experiences and challenges. Ecosystem Services 28: 105-114.

4. Adams VM, Setterfield SA, Douglas MM, et al. (2015) Measuring benefits of protected area management: Trends across realms and research gaps for freshwater systems. Philos Trans R Soc Lond B Biol Sci B 370.

5. Ketema, Derera (2017) Ethiopia: Changes from "people out approach" protected area management to participatory protected area management? Insight from Ethiopian protected areas. IOSR Journal of Environmental Science, Toxicology and Food Technology 11: 49-55.

6. Vreugdenhil D, Vreugdenhil AM, Tilahun T, et al. (2012) Gap analysis of the protected areas system of Ethiopia. Ethiopian Wildlife Conservation Authority, Addis Ababa, Ethiopia.

7. Nishizaki Nobuko (2014) "Neoliberal conservation" in Ethiopia: An analysis of current conflicts in and around protected areas and their resolution. African Study Monographs Suppl 50: 191205.

8. Tefera Melaku (2011) Wildlife in Ethiopia: Endemic large mammals. World Journal of Zoology 6: 108-116.

9. Scholes RJ, Biggs RA (2004) Ecosystem services in Southern Africa a regional assessment.

10. Tessema Mekbeb E, Lilieholm Robert J, Ashenafi Zelealem T, et al. (2010) Community attitudes toward wildlife and protected areas in ethiopia. Society \& Natural Resources 23: 489-506.

11. Council of Ministers (2008) Council of ministers regulations to provide for wildlife development, conservation and utilization. Council of Ministers Regulation No 163/2008, Addis Ababa, Ethiopia, 4567-4600.

12. Michael J Jacobs, Catherine A Schloeder (2001) Impacts of conflict on biodiversity and protected areas in Ethiopia. Biodiversity Support Program, Washington DC, 45.

13. Desalegn W (2004) Strategies for sustainable management of biodiversity in the Nech Sar National Park, Southern Ethiopia. A research report submitted to organization for social science research in Eastern and Southern Africa (OSSREA), Addis Ababa, Ethiopia. 
14. Worboys GL, Trzyna T (2015) Managing protected areas. In: GL Worboys, M Lockwood, A Kothari, S Feary, I Pulsford, Protected area governance and management. (edn), ANU Press, Canberra, 207-250.

15. Central Statistical Agency (2013). Population projection of Ethiopia for all regions, at Woreda level from 2014-2017, Addis Ababa, Ethiopia.

16. Stephens PA, d'Sa CA, Sillero-Zubiri C, et al. (2001) Impact of livestock and settlement on the large mammalian wildlife of Bale Mountains National Park, Southern Ethiopia. Biological Conservation 100: 307-322.

17. Demeke Datiko, Afewerk Bekele (2011) Population Status and Human Impact on the Endangered Swayne's Hartebeest (Alcelaphus buselaphus swaynei) in Nechisar Plains, Nechisar National Park, Ethiopia. African Journal of Ecology 49: 311-319.

18. Kumssa T, Bekele A (2014) Attitude and perceptions of local residents toward the protected area of Abijata-Shalla Lakes National Park (ASLNP), Ethiopia. Journal of Ecosystem and Ecography 4: 1.

19. Yosef Mamo, Afework Bekele (2011) Human and livestock encroachments into the habitat of mountain Nyala (Tragelaphus buxtoni) in the Bale Mountains National Park, Ethiopia. Tropical Ecology 52: 265-273.

20. Biodiversity Indicators Development National Task Force (2010) Ethiopia: Overview of selected biodiversity indicators. Addis Ababa, Ethiopia, 48.

21. Bekele M (2003) Forest property rights, the role of the state, and institutional exigency: The Ethiopian experience. Swedish University of Agricultural Sciences, Uppsala, Sweden.

22. Chettiparamb A, Kokkranikal J (2012) Responsible tourism and sustainability: The case of Kumarakom in Kerala, India. Journal of Policy Research in Tourism, Leisure and Events 4: 302-326.

23. Spenceley A, Relly P, Keyser H, et al. (2002) Responsible tourism manual for South Africa. Department for Environmental Affairs and Tourism.

24. Niccolini F, Marzo D, Scipioni S, et al. (2019) Ecosystem services, socio-economic values and organizational profiles of Mediterranean MPAS.

25. Gough D, Oliver S, Thomas J (2017) An introduction to systematic reviews. Sage Publications Ltd.

26. Young J (2012) Ethiopian Protected Areas A 'snapshot'. A reference guide for future strategic planning and project funding, Ethiopian Wild Life Authority.

27. WDPA (2015) World data base report. Ethiopia.

28. Worboys GL (2015) Concept, purpose and challenges. In: GL Worboys, M Lockwood, A Kothari, S Feary, I Pulsford, Protected Area Governance and Management. (eds), ANU Press, Canberra, 9-42.

29. Vial F, Sillero-Zubiri C, Marino J, et al. (2011) An analysis of longterm trends in the abundance of domestic livestock and freeroaming dogs in the Bale Mountains National Park, Ethiopia. African Journal of Ecology 49: 91-102.

30. Atickem A, Bekele A, Williams SD (2010) Competition between domestic dogs and Ethiopian wolf (Canis simensis) in the Bale Mountains National Park, Ethiopia. African Journal of Ecology 48: 401-407.

31. Tadesse SA, Kotler BP (2013) The impacts of humans and livestock encroachments on the habitats of mountain Nyala (Tragelaphus buxtoni) in Munessa, Ethiopia.
32. Biru Y, Tessema ZK, Urge M (2017) Perception and attitude of pastoralists on livestock-wildlife interactions around Awash $\mathrm{Na}$ tional Park, Ethiopia: Implication for biodiversity conservation. Ecological Processes 6.

33. Bizuneh Tufa, Zerihun Girma, Girma Mengesha (2018) Humanlarge wild mammals conflict in Dhera-Dilfaqar Block of Arsi Mountains National Park, south eastern Ethiopia. Human Dimensions of Wildlife 23: 478-481.

34. Alemayehu Acha, Mathewos Temesgen, Hans Bauer (2018) Human-wildlife conflicts and their associated livelihood impacts in and around Chebera-Churchura National Park, Ethiopia. Society and Natural Resources 31: 260-275.

35. Getachew Mulualem, Weldemariam Tesfahunegny (2016) Review of key wildlife threats factors from literature and observation perspectives: A way forward for sustainable wildlife genetic resource conservation practices in Ethiopia. The Journal of Zoology Studies 3: 1-12.

36. Mohammed Kasso, Afework Bekele (2014) Threats to mammals on fragmented habitats around Asella Town, Central Ethiopia. International Journal of Biodiversity 2014.

37. Duffy R, St John FA, Büscher B, et al. (2016) Toward a new understanding of the links between poverty and illegal wildlife hunting. Conser Biol 30: 14-22.

38. Megaze A, Balakrishnan M, Belay G (2017) The attitudes and practices of local people towards wildlife in Chebera Churchura National Park, Ethiopia. International Journal of Biodiversity and Conservation 9: 45-55.

39. Nishizaki Nobuko (2005) Differing local attitudes toward conservation policy: A case study of Mago National Park, Ethiopia. African Study Monographs Suppl 29: 31-40.

40. Amare A (2015) Wildlife resources of Ethiopia: Opportunities, challenges and future directions: From ecotourism perspective: A review paper. Natural Resources 6: 405.

41. Belay S, Amsalu A, Abebe E (2014) Land use and land cover changes in Awash National Park, Ethiopia: Impact of decentralization on the use and management of resources. Open Journal of Ecology 4: 950-960.

42. Dechassa Lemessa, Matthew Perault (2001) Forest fires in Ethiopia: Reflections on socioeconomic and environmental effects of the fires in 2000. Journal of Oromo Studies 9: 96-130.

43. Johansson MU (2013) Fire and grazing in subalpine heathlands and forests of Bale Mountains, Ethiopia: Fire ecology and traditional use of fire. Swedish University of Agricultural Sciences, Umeå, Sweden.

44. Anteneh Belayneh, Temesgen Yohannes, Adefires Worku (2013) Recurrent and extensive forest fire incidence in the Bale Mountains National Park (BMNP), Ethiopia: Extent, cause and consequences. International Journal of Environmental Sciences 2: 2939.

45. Rutherford MC, Powrie LW, Schulze RE (1999) Climate change in conservation areas of South Africa and its potential impact on floristic composition: A first assessment. Diversity and Distributions 5: 253-262.

46. Hannah L, Midgley G, Andelman S, et al. (2007) Protected area needs in a changing climate. Frontiers in Ecology and the Environment 5: 131-138.

47. Newmark WD (2008) Isolation of African protected areas. Journal of Frontiers in Ecology and the Environment 6: 321-328. 
48. Mawdsley JR, O'Malley R, Ojima DS (2009) A review of climatechange adaptation strategies for wildlife management and biodiversity conservation. Conserv Biol 23: 1080-1089.

49. Hofmeister E, Rogall GM, Wesenberg K, et al. (2010) Climate change and wildlife health: Direct and indirect effects. USGS Science for the Changing World. International Journal of Biodiversity and Conservation 5: 572-583.

50. Yibekal Abebe (2012) Ecological and economic dimensions of the paradoxical invasive species-Prosopis juliflora and policy challenges in Ethiopia. Journal of Economics and Sustainable Development 3: 62-71.

51. Worboys GL, Lockwood M, Kothari A, et al. (2015) Protected area governance and management. ANU Press.

52. Asebe Regassa Debelo (2012) Contesting views on a protected area conservation and development in Ethiopia. Social Sciences 1: 24-43.

53. Federal Negarit Gazeta (1995) Proclamation of the Constitution of the Federal Democratic Republic of Ethiopia: 21 August 1995.

DOI: $10.36959 / 742 / 224$

Copyright: (c) 2020 Mengist W. This is an open-access article distributed under the terms of the Creative Commons Attribution License, which permits unrestricted use, distribution, and reproduction in any medium, provided the original author and source are credited. 